\title{
PENGARUH PENGGUNAAN MEDIA VIDEO ANIMASI TERHADAP MOTIVASI
}

\section{THE EFFECT OF USING ANIMATION VIDEO MEDIA ON MOTIVATION}

\author{
Ira Pratiwi*, Mochamad Ridwan \\ Pendidikan Olahraga, Universitas Negeri Surabaya, Surabaya, Indonesia \\ ${ }^{*}$ Corresponding Author : Ira Pratiwi, ira.18172@mhs.unesa.ac.id
}

Received: 2021-02-17; Revised: 2021-03-12; Accepted: 2021-04-24

\begin{abstract}
Abstrak
Penelitian ini memiliki tujuan untuk mengetahui pengaruh dan berapa besar dari penggunaan media video animasi terhadap motivasi mengikuti pembelajaran pendidikan jasmani, olahraga dan kesehatan. Metode yang digunakan yaitu metode quasi experiment dengan desain penelitian Non-Randomized Control Group Pretest-Posttest. Sampel penelitian ini yaitu siswa-siswi kelas VII-C dan VII-D SMP Negeri 20 Surabaya yang berjumlah 51 siswa. Pemilihan sampel penelitian ini diambil dengan teknik Probability sampling menggunakan cluster random sampling. Proses pengambilan data dilakukan dengan cara memberikan angket melalui google form yang dibagikan kepada sampel dan angket tersebut berisi tentang motivasi mengikuti pembelajaran pendidikan jasmani olahraga dan kesehatan. Teknik analisis data menggunakan uji normalitas dan uji homogenitas kemudian dilanjutkan uji pengaruh. Dari hasil pengolahan data dapat disimpulkan bahwa Ha diterima dan nilai pengaruh signifikan sebesar 38,3\%. Maka, dapat disimpulkan bahwa terdapat pengaruh adanya penggunaan media video animasi terhadap motivasi mengikuti pendidikan jasmani olahraga dan kesehatan. '
\end{abstract}

Kata Kunci: media video animasi, motivasi, siswa, pendidikan jasmani

\begin{abstract}
This study aims to determine the influence and how much of the use of animated video media on motivation to learn physical education, sports and health. The method used is a quasiexperimental method with a Pretest-Posttest Non-Randomized Control Group research design. The sample of this research is students of class VII-C and VII-D of SMP Negeri 20 Surabaya which collects 51 students. The sample of this research was taken by using probability sampling technique using cluster random sampling. The data collection process was carried out by providing a questionnaire through a google form which was distributed to the sample and the questionnaire contained the motivation for participating in sports and health learning. The data analysis technique used the normality test and homogeneity test, then continued with the effect test. From the results of data processing, it can be obtained that $\mathrm{Ha}$ is accepted and the significant effect value is $38.3 \%$. So, it can be said that there is an effect of using animated video media on motivation to participate in sports and health education.
\end{abstract}

Keywords: animated video media, motivation, students, physical education

How To Cite: Pratiwi, Ira., Ridwan, Mochamad. (2021). Pengaruh penggunaan media video animasi terhadap motivasi. Journal Of Sport Education (JOPE), 4 (1), 77-86. doi:http://dx.doi.org/10.31258/jope.4.1.77-86

Journal Of Sport Education (JOPE) is an open access article under the CC-BY-SA 4.0 


\section{PENDAHULUAN}

Pendidikan Jasmani, Olahraga dan Kesehatan (PJOK) termasuk bagian dari proses pendidikan yang dilakukan melalui aktivitas gerak yang bertujuan untuk meningkatkan dan mengembangkan kebugaran dan menciptakan suatu kesenangan atau kegembiraan melalui berbagaiaspek salah satunya emosional (Melyza \& Aguss, 2021). PJOK mengutamakan aktivitas jasmani atau aktivitas gerak serta pendidikan hidup sehat yang bertujuan selain menciptakan suatu kebugaran juga sebagai pertumbuhan dan perkembangan karakteristik, mental dan emosional agar selaras (Rahmatillah \& Hartoto, 2016). Pembelajaran PJOK tidak hanya melibatkan aktivitas gerak atau fisik tetapi melibatkan faktor psikis yang bertujuan sebagai perkembagan kecerdasan mental dan emosional yang dapat diimplementasikan pada saat proses pembelajaran aktivitas gerak berlangsung (Haris, 2018). PJOK mengembangkan keterampilan gerak, pengetahuan, pola hidup sehat dan bugar (Ridwan et al., 2020). PJOK juga termasuk mata pelajaran yang memiliki serangkaian perencanaan sebagai pendukung pelaksanaan peningkatan kualitas gerakan yang diberikan melalui berbagai macam cabang olahraga, tetapi dalam proses pembelajaran PJOK salah satu olahraga yang paling populer yaitu sepak bola (Darmawan et al., 2018). Proses pembelajaran PJOK dibutuhkan adanya suatu dorongan atau motivasi karena hal tersebut sangat berpengaruh dalam proses pembelajaran supaya berjalan dengan maksimal sesuai rancangan pembelajaran (Widiutama et al., 2021). Maka untuk meningkatkan motivasi atau dorongan diperlukan adanya media video supaya dapat memudahkan siswa untuk memahami dan menyerap materi yang diberikan serta pembelajaran terasa lebih menarik dengan adanya media tersebut (Aryanata et al., 2020).

Namun dengan kondisi pandemi pembelajaran PJOK harus dilakukan secara online atau melalui materi-materi yang diberikan tanpa praktek seperti biasanya. Sedangkan pada pembelajaran PJOK biasanya dilakukan secara tatap muka dan ada interaksi langsung antara guru dan murid dalam melaksanakan pembelajaran tersebut, tetapi dengan kondisi sekarang hanya dapat dilakukan melalui tetap maya tetapi materi tetap sama hanya saja cara penyampaiannya dikemas dengan cara yang berbeda atau dengan cara virtual dengan menggunakan media video berbasis animasi pada setiap materi. Dengan kondisi pembelajaran dalam jaringan (daring), proses pembelajaran masih kurang efektif karena tidak ada interaksi langsung dengan guru serta keterbatasan gadget yang digunakan dalam proses pembelajaran secara daring yang menjadi faktor penunjang, sehingga pembelajaran daring masih belum maksimal (Asmuni, 2020) . Tetapi hal tersebut tidak menjadi hal yang sulit, karena apapun cara yang dilakukan dalam proses pembelajaran pasti memiliki ukuran keberhasilan. Jadi dengan kondisi pembelajaran daring dapat melakukan pemanfaatan melalui media untuk menyampaikan materi seperti : media audio visual atau video animasi.

Media video animasi salah satu media pembelajaran yang menampilkan gambar dan tulisan yang menarik supaya mudah untuk dipahami dan ditirukan sehingga dapat membantu proses pembelajaran secara efektif (Huljannah \& Idrus, 2020). Media video animasi termasuk jenis media audio visual karena dalam media tersebut berisi tentang suara dan gambar. Media video animasi perlu dikembangkan pada masa pandemi saat pembelajaran secara daring atau hybrid karena dengan pembelajaran secara hybrid siswa cenderung cepat merasa bosan apabila media yang diberikan masih sederhana dan monoton karena pembelajaran jarak jauh memerlukan adanya suatu hal yang menarik agar tetap termotivasi (Sukarini \& Manuaba, 2021). Pengembangan media video animasi yang dikembangkan dengan adanya teknologi dapat meningkatkan kualitas hasil belajar siswa serta membantu guru dalam penyampaian materi melalui pengembangan media yang digunakan sebagai sarana untuk menyampaikan materi (Wulandari, 2019). Sehingga dengan adanya tampilan video animasi mengenai materi yang akan dipelajari dapat memberikan motivasi untuk mengikuti pembelajaran PJOK semakin meningkat, serta suasana proses pembelajaran yang tidak membosankan. Karena 
salah satu faktor yang berpengaruh dalam proses pembelajaran yaitu motivasi.

Motivasi bermanfaat sebagai suatu dorongan atau keinginan yang menggerakan seseorang agar melakukan sesuatu (Syahniar \& Dwi, 2018). Motivasi dapat berdampak pada psikis siswa karena motivasi termasuk hal yang berpengaruh pada kinerja tugas yang melelahkan sehingga dapat terjadi adanya kelelahan pada psikis, maka dalam proses pembelajaran motivasi harus tetap stabil agar tidak berdampak terhadap mental diri sendiri (Herlambang et al., 2021). Motivasi belajar menjadi hal yang penting dalam proses pembelajaran, karena hakikat dari motivasi belajar yaitu sebagai dorongan internal maupun eksternal agar perubahan tingkah laku dapat terarah walaupun motivasi tidak dapat diamati secara langsung tetapi secara langsung selama proses pembelajaran masing-masing siswa akan terlihat tingkat motivasinya berdasarkan tingkah laku di lapangan (Hartati, 2016). Motivasi belajar sangat penting terhadap hasil belajar karena motivasi memiliki tujuan untuk memberikan dukungan dalam menentukan tujuan dari suatu proses pembelajaran tersebut, jadi hasil belajar dapat ditentukan dengan berapa besar tingkat motivasi dalam pembelajaran tersebut yang artinya semakin tinggi motivasi maka semakin tinggi juga hasil belajarnya sedangkan apabila tingkat motivasi rendah maka hasil belajar juga rendah (Umam \& Hartati, 2014).

Berdasarkan penelitian terdahulu dengan judul "pengaruh penggunaan media animasi pada pembuat pola dasar badan wanita terhadap motivasi belajar" yang menggunakan metode deskriptif dan instrumen pengumpulan datanya menggunakan validasi dan praktialitas (Huljannah \& Idrus, 2020). Tetapi berbeda dengan penelitian ini yaitu menggunakan metode quasi experiment dengan instrumen pengumpulan data menggunakan angket melalui google form. Namun adanya penelitian ini memiliki perbedaan dan unsur kebaruan dibandingkan dengan penelitian yang sebelumnya. Jika penelitian yang sebelumnya melakukan penelitian untuk mengetahui tingkat motivasi belajar pendidikan jasmani, olahraga dan kesehatan berdasarkan variabel yang digunakan yaitu melalui suatu aktivitas atau permainan, tetapi hal ini memiliki perbedaan dalam menggunakan suatu media sebagai sarana yang tidak pernah digunakan karena selama pembelajaran pendidikan jasmani, olahraga dan kesehatan pembelajaran tersebut dilakukan secara praktek dilapangan. Maka setelah melakukan pengamatan dalam pembelajaran secara daring dan hybrid terdapat beberapa hal yang menarik dan berbeda, sehingga peneliti terdorong untuk melakukan penelitian mengenai media karena dengan melihat pembelajaran tersebut masih kurang menarik dari segi penyampaiannya. Pengembangan media pembelajaran termasuk salah satu faktor penunjang motivasi siswa dalam mengikuti pembelajaran, karena dalam pengembangan media melalui perkembangan teknologi informasi dapat berdampak positif bagi guru dan siswa sehingga guru dapat menggunakan teknologi tersebut dengan berbagai macam bentuk yang menarik (Mislan \& Santoso, 2019). Kondisi pembelajaran secara daring menuntut para guru untuk melakukan suatu perubahan terhadap konsep pembelajaran dengan berbagai inovasi melalui berbagai pengembangan pada media pembelajaran agar pembelajaran PJOK tetap dapat dilakukan meskipun pembelajaran dilakukan secara daring (Kanca et al., 2021). Berbagai macam teknologi dan platform yang canggih dserta modern dapat dimanfaatkan pada kondisi pembelajaran yang dilakukan secara daring karena pembelajaran PJOK tidak hanya belajar mengenai teori namun ada materi praktek sehingga meskipun pembelajaran secara daring semua materi tetap tersampaikan melalui inovasi dari media pembelajaran (Jayul \& Irwanto, 2020).

Oleh karena itu penelitian ini dilakukan dengan menggunakan media sebagai variabel yaitu karena dalam pembelajaran pendidikan jasmani,olahraga dan kesehatan masih kurang dalam penggunaan media-media karena pembelajaran pendidikan jasmani, olahraga dan kesehatan dilakukan secara praktik. Tujuan dalam penelitian ini untuk mengetahui pengaruh dari penggunaan media video animasi terhadap motivasi mengikuti pembelajaran pendidikan 
Journal Of Sport Education (JOPE), 4 (1) 2021 - 80

Ira Pratiwi*, Mochamad Ridwan

jasmani, olahraga dan kesehatan pada siswa kelas VII di SMP Negeri 20 Surabaya.

\section{METODE}

Metode yang digunakan dalam penelitian ini yaitu metode quasi experiment dengan desain penelitian Non-Randomized Control Group Pretest-Posttest Design karena subjek dalam penelitian ini tidak dipilih secara acak dan ada kelompok kontrol namun pada desain ini dapat diketahui hasilnya dari adanya perlakuan yang telah diberikan dan menggunakan pendekatan kuantitatif, sebab dalam penelitian tersebut datanya berupa angka atau numerik yang digunakan untuk menentukan hasil perbedaan dari perlakuan yang diberikan. Metode penelitian eksperimen merupakan metode yang dapat digunakan untuk menguji adanya hubungan sebab akibat sehingga dapat diketahui pengaruh adanya pemberian perlakuan (Prasetyo et al., 2020). Populasi dan sampel merupakan siswa-siswi kelas VII SMP Negeri 20 Surabaya. Pemilihan sampel dalam penelitian ini diambil dengan teknik Probability sampling menggunakan cluster random sampling karena sampel diambil secara kelompok dimana sampel tersebut merupakan siswa-siswi kelas VII-C dan VII-D SMP Negeri 20 Surabaya yang berjumlah 51 siswa yang terbagi menjadi 2 kelas yaitu kelas kontrol dan kelas eksperimen. Instrumen yang digunakan dalam penelitian tersebut yaitu angket. Angket tersebut yang digunakan untuk mendapatkan data dari responden yang diberikan melalui google form karena dengan kondisi proses pembelajaran secara daring tidak memungkinkan untuk melakukan pengambilan data secara luring. Pertanyaan angket tersebut membahas mengenai motivasi mengikuti PJOK. Angket tersebut uji validitasnya sebesar 0.986 dan uji reliabilitasnya sebesar 0.867 sehingga sudah layak digunakan. Instrumen dan prosedur penelitian yaitu menggunakan angket terbuka yang terdiri dari 19 pertanyaan yang berisi tentang motivasi belajar PJOK. Indikatornya terdiri dari attention, relevance, confidence, satisfaction (Keller \& M, 2010). Angket yang digunakan untuk mendapatkan data dari responden yaitu berupa link google form untuk diisi oleh responeden tersebut. Proses pemberian angket tersebut diberikan secara online melalui whatsapp group kelas karena pembelajaran yang dilakukan secara hybrid dan tidak memungkinkan untuk diberikan secara tatap muka, namun untuk pemberian perlakuan dilakukan secara hybrid sesuai pembelajaran biasanya. Pertanyaan angket tersebut membahas mengenai motivasi mengikuti PJOK. Angket tersebut uji validitasnya sebesar 0.986 dan uji reliabilitasnya sebesar 0.867 sehingga sudah layak digunakan.

Teknik analisis data dalam penelitian ini menggunakan aplikasi SPSS versi 21. Dengan cara melakukan uji normalitas untuk mengetahui bahwa data tersebut berdistribusi normal dengan ketentuan apabila sig 2 tailed $<0,05$ atau bisa disebut Ho diterima dan data tersebut berdistribusi normal. Kemudian dapat dilanjutkan dengan melakukan uji homogenitas dengan ketentuan sig 2 tailed >0,05 sedangkan pada hasil penelitian ini uji homogenitasnya menghasilkan nilai 0,455 yang artinya nilai tersebut $>0,05$ dan dapat disimpulkan bahwa hasil uji tersebut signifikan. Selanjutnya setelah dilakukan uji normalitas dan uji homogenitas yang hasilnya signifikan maka dilakukan uji signifikasi untuk mengetahui berapa besar pengaruh adanya perlakukan yang diberikan. Pada uji signifikasi ini dapat disimpulkan signifikan apabila hasil signifikan <0,05 dan dalam uji signifikasi penelitian ini menghasilkan nilai signifikasi sebesar 0,000 yang artinya terdapat pengaruh dengan adanya perlakuan yang diberikan. Setelah mengetahui adanya pengaruh dalam data tersebut maka dapat dilakukan perhitungan dengan model summary kemudian dilihat dari hasil R-Square untuk mengetahui prosentase pengaruh tersebut. Dan dari hasil R Square memiliki nilai sebesar 0,383 atau 38,3\%. Jadi dapat disimpulkan bahwa pengaruh penerapan media video animasi terhadap motivasi mengikuti PJOK sebesar 38,3\%. 
Journal Of Sport Education (JOPE), 4 (1) 2021 - 81

Ira Pratiwi*, Mochamad Ridwan

Tabel 1. Desain Non-Randomized Control Group Pretest-Posttest

$\begin{array}{llr}\mathrm{T} 1 & \sim & \mathrm{T} 2 \\ \mathrm{~T} 1 & \mathrm{X} & \mathrm{T} 2\end{array}$

Desain ini termasuk jenis desain yang menggunakan kelompok kontrol dan adanya pretest-posttest, keterangan simbol dalam desain ini yaitu T1 berarti tes awal, T2 berarti tes akhir, berarti tidak ada perlakuan, X berarti ada perlakuan (Maksum, 2018)

\section{HASIL}

\section{Uji Normalitas}

Uji normalitas dilakukan untuk mengetahui apakah data yang dianalisis berdistribusi normal atau tidak. Oleh karena itu, uji normalitas dapat dilakukan dengan cara perhitunggan dengan SPSS 21. Ketentuan dalam uji normalitas yaitu jika sig 2 tailed <0,05 termasuk kategori normal atau Ho diterima, Ha ditolak dan persebaran data tidak normal. Sedangkan apabila nilai signifikafikan lebih besar dari 0,05 maka Ha diterima, Ho ditolak dan persebaran data normal. Berikut hasil pengujian normalitas menggunakan SPSS 21:

Tabel 2. Uji Normalitas

\begin{tabular}{lcccc}
\hline & \multirow{2}{*}{ media video animasi } & \multicolumn{3}{c}{ Kolmogorov-Smirnov $^{\mathrm{a}}$} \\
\cline { 3 - 5 } Motivasi mengikuti PJOK & kelas control &, 192 & 26 & Sig. \\
& kelas eksperimen &, 165 & 25 &, 015 \\
\hline
\end{tabular}

Berdasarkan tabel di atas dapat dijelaskan bahwa pada kelas kontrol nilai signifikan ,015 lebih besar dari 0,05 dan untuk kelas eksperimen nilai signifikan 0,78 lebih besar dari 0,05. Dengan demikian dapat disimpulkan bahwa dalam kelas kontrol maupun kelas eksperiman Ha diterima sedangkan Ho ditolak yang diartikan bahwa persebaran data tersebut normal.

\section{Uji Homogenitas}

Tabel 3. Uji homogenitas

\begin{tabular}{cccc}
\hline Levene Statistic & df1 & df2 & Sig. \\
\hline, 568 & 1 & 49 &, 455 \\
\hline
\end{tabular}

Berdasarkan tabel di atas diperoleh nilai signifikan yaitu 0,455 yang artinya $>0,05$ maka dapat disimpulkan bahwa data tersebut data Homogen.

\section{Uji Signifikasi}

Uji signifikasi dilakukan untuk melihat ada tidaknya pengaruh media video animasi terhadap motivasi mengikuti PJOK. Uji signifikasi dilakukan setelah uji normalitas dan uji homogenitas, dengan ketentuan hasil apabila hasil signifikan <0,05 atau tidak lebih dari 0,05.

Tabel 4. Uji pengaruh

\begin{tabular}{lrrrrr}
\hline Model & Sum of Squares & Df & Mean Square & F & \multicolumn{1}{c}{ Sig. } \\
\hline Regression & 4,884 & 1 & 4,884 & 30,443 &, $000^{\mathrm{b}}$ \\
Residual & 7,861 & 49 &, 160 & & \\
Total & 12,745 & 50 & & & \\
\hline
\end{tabular}


Journal Of Sport Education (JOPE), 4 (1) 2021 - 82

Ira Pratiwi*, Mochamad Ridwan

Tabel 5. Model Summary

\begin{tabular}{rrrrr}
\hline Model & R & R Square & Adjusted R Square & Std. Error of the Estimate \\
\hline 1 &, $619^{a}$ &, 383 &, 371 &, 401 \\
\hline
\end{tabular}

Berdasarkan tabel 4 perhitungan uji pengaruh dan nilai signifikasi sebesar 0,000 atau $<0,05$ maka dapat disimpulkan bahwa terdapat pengaruh terhadap variabel independen yang digunakan untuk mengukur variabel dependent. Dan dari hasil R Square pengaruh yang dihasilkan yaitu sebesar $38,3 \%$.

\section{PEMBAHASAN}

Dari hasil pengujian data di atas terdapat pengaruh dengan adanya penggunaan media video animasi terhadap motivasi mengikuti pembelajaran PJOK pada saat pembelajaran hybrid. Penerapan pengembangan media dalam hybrid learning mengalami peningkatan (Amalia \& Sudarwanto, 2022). Pada pembelajaran hybrid maupun daring sangat diperlukan suatu pendorong agar siswa tidak merasa jenuh atau bosan saat proses belajar mengajar berlangsung baik secara daring maupun hybrid. Motivasi siswa sangat penting agar mereka memiliki suatu dorongan untuk lebih semangat dan giat dalam proses pembelajaran. Memastikan jika motivasi belajar siswa timbul karena adanya pemakaian media pembelajaran (Sunami \& Aslam, 2021). Peranan guru dalam memberikan informasi sebelum memulai pembelajaran juga berpengaruh terhadap motivasi ekstrinsik atau motivasi yang berasal dari luar diri siswa (Aina et al., 2020). Motivasi ekstrinsik lebih berpengaruh karena dalam motivasi ekstrinsik ditemukan beberapa unsur sehingga lebih mendominasi agar termotivasi (Khoirunnisa \& Ulfah, 2021). Salah satunya adalah video animasi yang dirancang semenarik mungkin yang membuat siswa mau mencermati serta mempunyai semangat belajar. Video animasi sama dengan audio visual. Audio visual yang mencampurkan antara gambar dan suara. Video animasi di tambahkan animasi yang sketsanya seolah- olah menjadi hidup yang membuat menarik dalam video tersebut. Media pembelajaran yang menarik sangat berpengaruh dalam upaya meningkatkan motivasi belajar siswa (Farindhni, 2018). Penelitian ini menggunakan media animasi supaya siswa lebih termotivasi karena suatu pembelajaran dapat maksimal dan berhasil apabila pengemasan dan penyampaian materi yang diberikan mudah dipahami oleh siswa sehingga salah satu cara yang dapat digunakan dalam pembelajaran kondisi pandemi yaitu melalui media atau sarana dalam penyampaian materi (Bernhardin \& Rahmani, 2020).

Media salah satu sumber yang sangat diperlukan dalam pembelajaran (Widiyasanti \& Margareta Proketen, 2018). Media termasuk sarana yang membawa informasi antara sumber dan penerima informasi (Smaldino et al., 2012). Media pembelajaaran dapat digunakan sebagai sarana untuk memvisualisasikan dari materi yang digunakan selama proses belajar mengajar (Supardi et al., 2015). Oleh sebab itu, media bisa membantu aktivitas dan interaksi siswa dengan guru dalam proses pembelajaran. Media video animasi ialah media yang menunjukkan modul pembelajaran berbentuk video yang terbuat dengan sebagian gambar diam dengan sedikit pergantian dari satu keberikutnya yang ditampilkan dalam waktu yang kilat serta diproyeksikan sehingga menciptakan suatu ilusi gerak. Melalui penggunaan media video animasi pada materi aktivitas bola besar melalui permainan sepak bola dapat menjadikan pembelajaran memiliki inovasi yang baru. Karena apabila sebelumnya pembelajaran PJOK hanya dilakukan di lapangan secara praktek namun dengan adanya pembelajaran secara hybrid maka ada bentuk variasi-variasi yang dapat digunakan yang sebelumnya belum pernah diberikan. Penyebaran angket kepada kelas eksperimen banyak menarik perhatian di dalamnya, karena siswa merasa senang dengan adanya animasi yang 
selama ini sangat jarang dalam pembelajaran PJOK menampilkannya. Lain halnya dengan kelas kontrol menanggapi dengan jawaban "biasa saja", karena dalam penelitian ini kelas kontrol hanya diberikan sebuah perlakuan dengan tampilan materi melalui media powerpoint sehingga tanggapannya berbeda dengan kelas eksperimen.

Selain itu, dalam penelitian ini tentunya memiliki berbagai manfaat bagi sekolah maupun bagi guru. Bagi sekolah dengan adanya penelitian ini dapat memberikan bantuan yang positif untuk memperbaiki proses pembelajaran melalui media video animasi khusunya pada mata pelajaran pendidikan jasmani, olahraga dan kesehatan. Sedangkan manfaat bagi guru yaitu dapat membantu guru untuk mengetahui dan memahami bahwa dalam pembelajaran pendidikan jasmani, olahraga dan kesehatan banyak perangkat atau media yang dapat digunakan tanpa harus praktek secara langsung serta dengan adanya media yang belum pernah diberikan karena biasanya pada pembelajaran pendidikan jasmani olahraga dan kesehatan diberikan contoh atau peraga secara langsung.

Menurut hasil penelitian dari pengaruh penggunaan media video animasi terhadap motivasi mengikuti PJOK, dapat diketahui bahwa pengaruh media video animasi terhadap motivasi mengikuti PJOK yaitu sebesar 38,3\% karena sebelumnya pada saat pembelajaran PJOK siswa hanya diberikan tayangan berupa video tanpa ada inovasi dalam video tersebut. Jadi, siswa lebih tertarik apabila diberikan media video yang unik sehingga mudah dimengerti dan dengan pemberian media video animasi tersebut maka siswa lebih termotivasi untuk mengikuti pembelajaran PJOK. Dari penelitian lain juga terdapat peningkatan dengan adanya media audio visual dalam pembelajaran secara daring (Simbolon et al., 2021). Penelitian yang dilakukan oleh (Sukma \& Puspasari, 2021) menyatakan bahwa penerapan media audiovisual berpengaruh terhadap motivasi belajar siswa yang dibuktikan dengan hasil hitung nilai signifikasi sebesar 20,722 >1,659. Berdasarkan hasil dari penelitian sebelumnya dengan hasil nilai post test tanpa perlakuan berbasis animasi sebesar 27,2 sedangkan pada post test dengan perlakuan berbasis animasi memperoleh nilai sebesar 33,35 yang dapat disimpulkan bahwa penerapan model jigsaw berbasis animasi berpengaruh terhadap keterampilan gerak dasar shooting (Juditya \& Aprila, 2018).

\section{SIMPULAN}

Berdasarkan hasil penelitian yang dilakukan mengenai pengaruh penggunaan media video animasi terhadap motivasi mengikuti PJOK dapat disimpulkan bahwa adanya pengaruh yang signifikan dari penggunaan media video animasi pada saat pembelajaran secara hybrid terhadap motivasi mengikuti PJOK pada siswa kelas VII di SMP Negeri 20 Surabaya. Penelitian ini tentunya memiliki beberapa hal yang menjadi suatu keterbatasan yaitu dengan sistem pembelajaran secara hybrid yang artinya pembelajaran dilakukan dengan dua konsep yaitu pembelajaran secara tatap maya dari rumah dan tatap muka di sekolah. Namun walaupun tatap muka di sekolah tetap melakukan pembelajaran di kelas dan belum praktek secara langsung seperti semula di lapangan. Dan berdasarkan hasil penelitian yang mengalami pengaruh signifikan maka peneliti memberikan rekomendasi untuk guru agar dapat mencoba memberikan materi menggunakan media tersebut agar siswa lebih termotivasi dalam proses pembelajaran.

\section{DAFTAR PUSTAKA}

Aina, M., Budiarti, R. S., Muthia, G. A., \& Purba, D. A. P. B. (2020). Motivasi Belajar Biologi Peserta Didik SMA pada Pembelajaran Daring selama Pandemi Covid-19. Journal of Biology Education Research, 1(1), 1-14.

Amalia, R. I., \& Sudarwanto, T. (2022). Pengembangan Media Booklet Berbasis Hybrid Learning Pada Mata Pembelajaran Marketing Kompetensi Dasar Menganalisis Pasar Kelas X Bisnis 
Daring Dan Pemasaran Smk Negeri 10 Surabaya. 10(1), 1564-1572.

Aryanata, I. W. Y., Jampel, I. N., \& Mahadewi, L. P. P. (2020). Media Video Pembelajaran Teknik Dasar Bermain Bola Voli Pada Pelajaran Penjaskes. Jurnal Penelitian Dan Pengembangan Pendidikan, 4(2), 186. https://doi.org/10.23887/jppp.v4i2.27164

Asmuni. (2020). Problematika Pembelajaran Daring di Masa Pandemi Covid-19 dan Solusi Pemecahannya. Jurnal Paedagogy: Jurnal Penelitian Dan Pengembangan Pendidikan, 7(4), 281-288. https://e-journal.undikma.ac.id/index.php/pedagogy

Bernhardin, D., \& Rahmani, A. R. (2020). Pembelajaran On-Line: Pengunaan Media Pembelajaran Audio Visual Berbasis Digital terhadap Penguasaan Gerak Dasar Lay Up. Jpoe, 2(2), 260-266. https://doi.org/10.37742/jpoe.v2i2.119

Darmawan, G., Ridwan, M., \& Prakoso, B. B. (2018). Football Learning Outcome Measurement Model Validity, Reliability, and Objectivity. Educational Research International, 7(November), 29-35.

Farindhni, D. A. (2018). Pengembangan Media Video Animasi Untuk Peningkatan Motivasi Belajar Dan Karakter Demokratis Siswa Kelas V Sekolah Dasar. Jurnal Pendidikan Karakter, 8(2), 172-186. https://doi.org/10.21831/jpk.v8i2.21850

Haris, I. N. (2018). Model pembelajaran peer teaching dalam pembelajaran pendidikan jasmani. Journal of Chemical Information and Modeling, 4(9), 2. file://C:/Users/asus/Downloads/191-Article Text-651-2-10-20180222.pdf

Hartati, S. C. Y. (2016). Penerapan Modifikasi Permainan Softball Terhadap Motivasi Belajar Siswa Dalam Pembelajaran Pendidikan Jasmani, Olahraga dan Kesehatan. Jurnal Pendidikan Olahraga Dan Kesehatan, 04 Nomer 0, 301-306.

Herlambang, M. B., Taatgen, N. A., \& Cnossen, F. (2021). Modeling motivation using goal competition in mental fatigue studies. Journal of Mathematical Psychology, 102, 102540. https://doi.org/10.1016/j.jmp.2021.102540

Huljannah, M., \& Idrus, Y. (2020). Pengaruh Penggunaan Media Animasi Pada Pembuat Pola Dasar Badan Wanita Terhadap Motivasi Belajar Siswa Kelas X Mata Pelajaran Pola Dasar Tata Busana SMK NEGERI 3 Payakumbuh. Jurnal Kapita Selekta Geografi, 3, 1-12.

Jayul, A., \& Irwanto, E. (2020). Model Pembelajaran Daring Sebagai Alternatif Proses Kegiatan Belajar Pendidikan Jasmani di Tengah Pandemi Covid-19. Jurnal Pendidikan Kesehatan Rekreasi, 6(2), 190-199.

Juditya, S., \& Aprila, R. N. (2018). Journal of Teaching Physical Education in Elementary School Pembelajaran Gerak Dasar Shooting Melalui Penerapan Model Jigsaw Berbasis Media Animasi. 1(2), 53-63.

Kanca, I. N., Swadesi, I. K. I., \& Budiawan, M. (2021). Bimbingan Teknis Penyusunan Perangkat Pembelajaran PJOK ditingkat SMP Masa Pandemi Covid-19. 1141-1147.

Keller, \& M, J. (2010). Motivation Design For Learning and Performance. 
Khoirunnisa, K., \& Ulfah, S. (2021). Profil Kecemasan Matematika dan Motivasi Belajar Matematika Siswa pada Pembelajaran Daring. Jurnal Cendekia: Jurnal Pendidikan Matematika, 5(3), 2238-2245. https://doi.org/10.31004/cendekia.v5i3.831

Maksum, A. (2018). Metodologi Penelitian. Unesa University Press.

Melyza, A., \& Aguss, R. M. (2021). Persepsi Siswa Terhadap Proses Penerapan Pembelajaran Pendidikan Jasmani Olahraga Dan Kesehatan Pada Pandemi Covid-19. Journal Of Physical Education, 2(1), 8-16.

Mislan, \& Santoso, D. A. (2019). Peran Pengembangan Media Terhadap Keberhasilan Pembelajaran PJOK di Sekolah. Prosiding Seminar Nasional IPTEK ..., 12-16. https://ejournal.unibabwi.ac.id/index.php/semnassenalog/article/view/585

Prasetyo, A. R., Kaloeti, D. V. S., Rahmandani, A., Salma, \& Ariati, J. (2020). Metode Penelitian Eksperimen. akultas Psikologi Universitas Diponegoro Semarang.

Rahmatillah, B., \& Hartoto, S. (2016). Penerapan Modifikasi Permainan Sepak Bola Terhadap Motivasi Siswa Dalam Pembelajaran Pendidikan Jasmani, Olahraga dan Kesehatan (Vol. 4).

Ridwan, M., Sudibyo, S., \& Kartiko, D. C. (2020). Aktifitas permainan, cuaca, dan motivasi siswa dalam pembelajaran pendidikan jasmani olahraga dan kesehatan. Journal of Sport Education (JOPE), 2(2), 40. https://doi.org/10.31258/jope.2.2.40-46

Simbolon, M. E. M., Lestari, N., Armanto, T., \& Alfarras, B. (2021). Efektivitas Pembelajaran PJOK Menggunakan Media Audio Visual saat Pandemi Covid-19 di Bangka Belitung. Jurnal Pendidikan Olahraga, 4(1), 1-8.

Smaldino, L., Lowther, D., \& L. \& Russel, J. D. (2012). Instructional Technology and Media for Learning (A. Rahman (ed.)). Pearson.

Sukarini, K., \& Manuaba, I. B. S. (2021). Pengembangan Video Animasi Pembelajaran Daring Pada Mata Pelajaran IPA Kelas VI Sekolah Dasar. Jurnal Edutech Undiksha, 9(1), 48-56. https://doi.org/10.23887/jeu.v9i1.32347

Sukma, T. G. A., \& Puspasari, D. (2021). Pengaruh Penggunaan Media AudioVisual terhadap Motivasi Belajar Siswa pada Mata Pelajaran Administrasi Umum Kelas X OTKP di SMKN 4 Surabaya. Journal of Economics and Business Education, 1, 1-12.

Sunami, M. A., \& Aslam. (2021). Pengaruh Penggunaan Media Pembelajaran Video Animasi Berbasis Zoom Meeting terhadap Minat dan Hasil Belajar IPA Siswa Sekolah Dasar. Jurnal Basicedu, 5(2), 1060-1066.

Supardi, S. U. S., Leonard, L., Suhendri, H., \& Rismurdiyati, R. (2015). Pengaruh Media Pembelajaran dan Minat Belajar Terhadap Hasil Belajar Fisika. Formatif: Jurnal Ilmiah Pendidikan MIPA, 2(1), 71-81. https://doi.org/10.30998/formatif.v2i1.86

Syahniar, S., \& Dwi, B. N. (2018). Hubungan Motivasi Belajar Dengan Hasil Belajar Matematika Siswa. Jurnal Counseling Care, 1(2), 17-24. https://doi.org/10.22202/jcc.2017.v1i2.2524 
Umam, F., \& Hartati, S. C. Y. (2014). Pengaruh Penerapan Modifikasi Permainan Sepak Takraw Terhadap Motivasi Belajar Siswa Dalam Pembelajaran Pendidikan Jasmani, Olahraga Dan Kesehatan (Studi Pada Siswa Kelas V SDN Jumput Rejo Buduran Sidoarjo). Jurnal Pendidikan Olahraga Dan Kesehatan, 2(1), 278-279.

Widiutama, P. A., Adi, I. P. P., \& Semarayasa, I. K. (2021). Motivasi Peserta Didik Mengikuti Pembelajaran PJOK di Masa Pandemi Covid-19. Indonesian Journal of Sport \& Tourism, 3(2), 71. https://doi.org/10.23887/ijst.v3i2.35433

Widiyasanti, \& Margareta Proketen. (2018). Pengembangan Media Video Animasi Untuk Meningkatkan Motivasi Belajar Dan Karakter Tanggung Jawab Siswa Kelas V. Jurnal Pendidikan Karakter, 8(1), 1-16. https://doi.org/10.21831/jpk.v8i1.21489

Wulandari, M. P. (2019). Keefektifan Penggunaan Media Video Animasi IPA SD Berbasis Literasi Sains Terhadap Hasil Belajar Siswa Kelas IV. ... PANCAR (Pendidik Anak Cerdas Dan Pintar ..., 3(2), 264-274. 